\title{
Assessing emissions levels and costs associated with climate and air pollution policies in South Africa
}

\author{
Lucas R.F. Henneman $^{\text {a,* }}$, Peter Rafaj ${ }^{\text {b }}$, Harold J. Annegarn ${ }^{c}$, Carmen Klausbruckner ${ }^{\text {d }}$ \\ a Georgia Institute of Technology, Atlanta, GA, USA \\ ${ }^{\mathrm{b}}$ International Institute for Applied Systems Analysis, Laxenburg, Austria \\ ${ }^{\mathrm{c}}$ Energy Institute, Cape Peninsula University of Technology, Cape Town, South Africa \\ d Johannes Kepler University, Linz, Austria
}

\section{H I G H L I G H T S}

- Estimates of emissions and costs provided for eight policy scenarios in South Africa.

- Integrated assessment was performed using the GAINS model.

- SA can exploit co-benefits of climate change mitigation and air pollution policies.

- Unintended policy contradictions can negatively impact air pollutant emissions.

\section{A R T I C L E I N F O}

\section{Article history:}

Received 2 July 2015

Received in revised form

18 November 2015

Accepted 26 November 2015

\section{Keywords:}

Integrated assessment

Air pollution

Climate change

GAINS

\begin{abstract}
A B S T R A C T
Affordable energy supply and reductions in emissions of local air pollution and greenhouse gases are each important aspects of South Africa's goals. Many traditional solutions, however, work in contradiction to one another. This work investigates effects on estimated emissions and costs of mitigation strategies using the Greenhouse Gas and Air Pollution Interaction Synergies (GAINS) model to identify policies that satisfy multiple goals. Eight scenarios that describe air pollution control options and mixes of energy production technologies are implemented in GAINS, which quantifies country-wide air pollution and greenhouse emissions and costs of controls. Emissions and costs trajectories are compared to the business as usual case, which projects $\mathrm{CO}_{2}$ emissions to increase by $60 \%$ by 2050 compared to 2015 . Results show that replacing all coal generation with renewables reduces $\mathrm{CO}_{2}$ emissions in 2050 by $8 \%$ compared to 2015, and that aggressive policy targeting the whole energy sector reduces $\mathrm{CO}_{2}$ emissions in 2050 by $40 \%$. GAINS is used to show co-benefits and tradeoffs of each scenario, such as reductions in emissions control costs that accompany a switch to renewables. The approach provides supporting evidence for policies that exploit co-benefits and avoid contradictions by assessing multiple aspects of the energy sector within the integrated framework provided by the GAINS modeling platform.
\end{abstract}

(c) 2015 Elsevier Ltd. All rights reserved.

\section{Introduction}

South Africa is committed to growing their economy. A key component of this goal is to provide and expand access to affordable energy to all its citizens and to industries. This energy, however, must be produced in a manner that both protects the health of citizens and the environment, and upholds the country's international commitments to address emissions of greenhouse gases (GHGs).

Many air pollutants are emitted when fossil fuels are

\footnotetext{
* Corresponding author.

E-mail address: lhenneman@gmail.com (L.R.F. Henneman).
}

combusted. Particulate matter (PM) has been linked in a number of studies to negative health effects. Exposure to household air pollution from solid fuels and ambient airborne PM ranked second and eighth in attributable disease burden in the 2013 Global Burden of Disease study (Lim et al., 2013). Other air pollutants, such as sulfur dioxide $\left(\mathrm{SO}_{2}\right)$ and oxides of nitrogen $\left(\mathrm{NO}_{x}=\mathrm{NO}+\mathrm{NO}_{2}\right)$, contribute to formation of secondary PM and ozone $\left(\mathrm{O}_{3}\right)$, a second air pollutant with known health effects, respectively.

Besides air pollutants that affect local human and ecological health, South Africa is concerned with reducing its contribution to rising GHGs concentrations in the atmosphere. Fossil fuel use in South Africa contributes to the country's standing as the world's 13th largest emitter of GHGs (U.S. EIA, 2013). 
The complex regulatory frameworks of energy, air pollution, and GHG policies are all related, and it is necessary to investigate them under a common framework. An integrated approach allows for co-benefits to be identified and exploited and for contradictions to be avoided. The Greenhouse Gas and Air Pollution Interactions and Synergies (GAINS) model provides such a framework (IIASA, 2012). This study presents an impact analysis of policies targeting the energy sector in South Africa, and investigates potentials for air pollutant and GHG emissions reductions under various pollution control and energy activity scenarios. To maintain coherence with the continuing national discussion on mitigation of climate change, the selected scenarios have been styled on commonly used scenarios in order to simulate policy options, such as those presented in the report "Study to Examine the Potential Socio-Economic Impact of Measures to Reduce Air Pollution from Combustion" (Scorgie et al., 2004) and the Long Term Mitigation Strategies (LTMS) report, a policy document that describes options available to South Africa to curb its carbon dioxide $\left(\mathrm{CO}_{2}\right)$ emissions (Energy Research Centre, 2007). Emissions of $\mathrm{SO}_{2}$, particulates with diameter less than $2.5 \mu \mathrm{m}\left(\mathrm{PM}_{2.5}\right), \mathrm{NO}_{x}$, and $\mathrm{CO}_{2}$ are estimated for each scenario along with the cost of air pollution controls.

The paper begins with a review of relevant energy policy in South Africa. A companion paper provides a more detailed analysis of the policy and legal framework in South Africa (Klausbruckner et al., In preparation). A description of the GAINS model precedes a detailing of the scenarios modeled and their relevance to policy options that South Africa has. Results from the GAINS model for each of these scenarios are summarized in Section 4 and analyzed further in the Section 5. The results will inform policy makers and future studies on impacts of energy systems both in South Africa and other countries that wish to apply the GAINS model for an integrated analysis to shape policy.

\section{Policy framework}

\subsection{Energy policy in South Africa}

South Africa has an energy-intensive economy. The country's index of primary energy supply per US dollar of gross domestic product (GDP) based on purchasing power parity is 11.7 mega joules (MJ), which outranked both Asia (7.9 MJ/USD) and Latin America (6.7 MJ/USD) in 2007 (Winkler, 2007). Over 90\% of the electricity in South Africa is produced by burning coal (Edkins et al., 2010). Industry, transport, mining, and agriculture make up the top four demand sectors (Winkler, 2007).

Historically, South Africa had an excess of electricity generation capacity to supply the demand, which contributed to the country having among the lowest electricity prices in the world (\$0.02/ $\mathrm{kWh}$ or less). For diverse reasons, including a protracted period of 20 years in which no new generating plants were built, this situation has changed in recent years (2008 onwards) so that supply has not always been able to meet demand. From 2008 onwards, the country saw increasing prices and intermittent load shedding (scheduled blackouts on a planned regional basis) (Edkins et al., 2010; Tait and Winkler, 2012). In 2015, Eskom, the state-owned electricity utility, planned to begin operation of the first of two new coal-fired power plants currently under construction, each with a planned capacity of $4800 \mathrm{MW}$ electric (MWe) (Kiratu, 2010).

In 2007, the South African Government commissioned the LTMS report, to investigate pathways that the country could take to mitigate national emissions of GHGs (Energy Research Centre, 2007). This report presented scenarios and policy options that would allow the country to follow a "required by science" emissions pathway that aligns with worldwide emissions reductions of 30-40\% below 2003 levels in 2050 necessary to keep global warming below $2{ }^{\circ} \mathrm{C}$ (IPCC, 2001). Four policy timeline options are proposed as necessary for achieving the required by science pathway in the report - "Start Now," "Scale Up," "Use the Market," and "Reach for the Goal". Each of these describes a suite of policies that, if each implemented in full, would achieve $64 \%$ of the reductions in GHG emissions needed in the "required by science" scenario. The options suggest a combination of investment in both positive and negative cost technologies (i.e., technologies that do not repay their value over time), taxes and incentives, and behavioral change. This document has formed the basis for national climate change policy since 2007 , however, there has been a lack of coordinated effort to implement these policies. The LTMS, for instance, proposed eliminating the commissioning of new coal plants, and Eskom has since begun building the two new plants mentioned above (Kiratu, 2010), while the low-carbon (but otherwise still controversial) nuclear power option has been subjected to repeated delays, although a tentative deal was reached in 2014 with the Russian company Rosatom to supply 9.6 GWe of nuclear capacity to South Africa by 2030 (World Nuclear Association, 2014).

\subsection{Air quality policy in South Africa}

South Africa routinely experiences levels of air pollution that are detrimental to human health in many areas of the country. Besides ambient air quality issues caused by industrial and mobile sources, many poorer communities suffer negative health outcomes due to exposure to high levels of pollution from fossil fuels used for cooking, heating, and lighting (Scorgie et al., 2004; Pauw et al., 2008).

The National Environmental Management Air Quality Act, promulgated in 2004, formed the legal basis for defining Minimum Emissions Standards (MES) for regulating gaseous and particulate emissions from industrial operations. The MES apply to both new and existing plants in industrial and electricity generating sectors, were amended in 2013 and come into effect in 2015. The effectiveness of this regulation may be limited; however, as many of the major emitters have applied for deferments of the date of compliance with the MES (Myllyvirta, 2014). Extensions through 2020 have been granted to certain plants for $\mathrm{SO}_{2}$ and $\mathrm{NO}_{x}$ emissions.

Regarding mobile emissions, the sale of fuel with high sulfur content (up to $500 \mathrm{ppb}$ ) has limited the ability of automobile manufacturers to sell vehicles with engines that employ the current cleanest technology. In 2012, the government issued a Government Notice specifying the compulsory introduction of fuels that meet EURO 5 standards (less than 10 ppm sulfur) by July 2017. While there has been some effort to begin marketing these fuels already, the enforcement of regulations on low-sulfur fuels may be postponed, which would delay widespread introduction of higherstandard fuels (SAPIA, n.d.). A recent agreement by South Africa suggests that enforcement of low-sulfur fuels will occur begin in 2020 (Workshop, 2015).

\subsection{Climate change mitigation policy in South Africa}

In 2009, at the United Nations Framework Convention on Climate Change (UNFCCC) Conference of the Parties (COP 15) in Copenhagen, South African President Zuma pledged a target of $\mathrm{CO}_{2}$ emissions reductions below "business as usual" of 34\% by 2020 and $42 \%$ by 2025 (Kiratu, 2010) (subject to conditons on the provision of financial support). These targets came as a surprise to many South African policy makers and industry leaders at the time (Kiratu, 2010), but there has since been some progress in 
formulating policies to reduce GHG emissions in line with these pledges. In 2010, the government developed an Integrated Resources Plan (IRP), which set a goal that renewable energy will make up $14 \%$ of the electricity generating mix by 2030 (Merven et al., 2014; DOE, 2013). The LTMS report found that a tax on carbon emissions would be the most efficient policy to reduce $\mathrm{CO}_{2}$ emissions, and such a tax was proposed to begin in 2015, but implementation has been delayed to 2016 (Merven et al., 2014). Results of the LTMS were further used to inform the creation of the 2011 National Climate Change Response White Paper (S.A. Government, 2011). This document laid out plans to peak emissions between 2020 and 2025, plateau until 2035, and decrease annual emissions thereafter. The White Paper states that the government will prioritize policy actions that address both GHG emissions and negative public health outcomes due to local air pollution exposure. The government hopes to implement a solution that achieves reductions in GHG emissions and maintains its competitiveness on the global level (S.A. Government, 2011).

Under the original IRP published in 2010, South Africa would reduce dependence on coal for electricity production from $90 \%$ to $65 \%$ in 2030 . The share of electricity produced would be $20 \%$ from nuclear and to $14 \%$ from renewables in 2030. An updated IRP published in 2013 presents decision trees to enable decisionmaking in a changing economic climate. Under this plan, the Department of Energy aims to fund projects that will install a generating capacity of $3.7 \mathrm{GW}$ ( $8.4 \%$ of total generating capacity) by renewables by 2015; however, the capacity is somewhat behind this goal (Merven et al., 2014). These policies and the deal to increase nuclear capacity show that the government is aware of the need for climate change mitigation policies and is taking action to curb emissions.

\section{Methods}

\subsection{The GAINS model}

The International Institute for Applied Systems Analysis (IIASA) developed the GAINS techno-economic optimizing model to evaluate effects of air pollution controls and GHG emissions reduction policies on air pollutant emissions, public and environmental health, and abatement costs (IIASA, 2012). GAINS was designed to be easily adapted to different world regions, and has been applied to a number of regions and individual countries around the world, including Europe (Amann et al., 2011; Wagner et al., 2013; Winiwarter, 2005), China (Amann et al., 2008), Pakistan (Purohit et al., 2013) and others. Applications have included studying the costs and benefits of climate-mitigation policies, the joint benefits of climate change mitigation and air pollution control policies, and the health benefits of reducing air pollution emissions (Rafaj et al., 2013).

GAINS has the capability to estimate emissions of both GHGs (including $\mathrm{CO}_{2}, \mathrm{CH}_{4}, \mathrm{~N}_{2} \mathrm{O}$, and fluorinated gases) and local air pollutants (including $\mathrm{SO}_{2}, \mathrm{NO}_{\mathrm{x}}$, volatile organic compounds-VOCs, $\mathrm{NH}_{3}$, and $\mathrm{PM}$ ). At its core, the model applies a single equation that calculates emissions using data entered by the user (Winiwarter, 2005). In past applications, it has been combined with cost-optimization, chemical transport, and epidemiological models. These three extensions require additional models that are not included in the current study; for this application, only the emissions and cost calculations are applied.

$E_{p}=\sum_{j, a, t} A_{j, a} e f_{j, a, p}\left(1-e f f_{t, p}\right) X_{j, a, t}$

j,a,t,p Subscripts denoting sector, activity, abatement technology, and pollutant, repectively

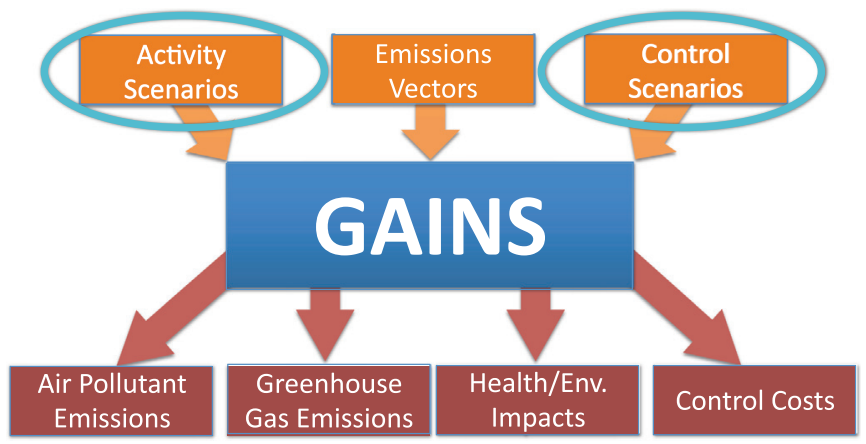

Fig. 1. Schematic representing the inputs and outputs of the current implementation of GAINS. The ovals denote the inputs that are adjusted to create the eight scenarios assessed in this work.

$E_{p}$ Emissions of pollutant $p$

$A_{j}$ Activity in sector $j$

$e f_{j, a, p}$ Uncontrolled emissions factor in sector $j$ of activity $a$ and pollutant $p$

eff $f_{t, p}$ Reduction efficiency of abatement technology $t$ on pollutant $p$

$X_{j, a, t}$ Implementation rate of technology $t$ sector $j$ and activity $a$.

The graphical representation of this equation (Fig. 1) highlights the two inputs - activity ( $A$ in the equation above) and emission controls ( $X$ in the equation above) - that are adjusted to create the scenarios. Emissions vectors (ef and eff in the equation above) represent constants that are unique to each activity or abatement technology.

While GAINS is a powerful tool that can be used to analyze the emissions, public health, and economic outcomes of different scenarios, it does have limitations. First, the activity inputs to GAINS are developed outside of the model. For instance, it does not model electricity demand based on price, which has an effect on the emissions from the electricity generation sector (i.e., GAINS is not an electricity dispatching tool). Other factors, such as population growth, deployment of new power supply technologies (e.g. renewables), and improved efficiency are modeled in separate energy models, and not within GAINS.

Control costs are estimated in GAINS by assuming a cost for each control technology per amount of pollutant controlled. These are multiplied by the amount of pollutant that is controlled with each technology at a given application rate. A $4 \%$ interest rate is used in this study.

This paper presents the initial implementation of GAINS in South Africa, in which only a limited range of GAINS outputs are assessed. Other air pollutants (e.g. ammonia, VOCs) and non- $\mathrm{CO}_{2}$ GHGs, although covered by the GAINS modeling framework, are not included in the analysis presented herein. Functions to model health outcomes require the inclusion of data layers generated by external dispersion and epidemiological models that have not as yet been included in the South African GAINS domain. The current implementation deals with the overall energy and total national emissions of the defined scenarios.

\subsection{Scenario development}

The modeling was performed using eight scenarios (Table 1). These were split into two varieties: control scenarios and activity scenarios. Scenarios were designed to reflect similar scenarios presented in previous modeling efforts (for instance, in the LTMS and Gauteng Integrated Energy Strategy (DLGH, 2010; Scorgie et al., 2004)). 
Table 1

Control and Activity scenarios employed in modeling.

\begin{tabular}{|c|c|c|}
\hline Scenario & Acronym & Notes \\
\hline \multicolumn{3}{|l|}{ Baseline scenario } \\
\hline Business as usual & BAU & $\begin{array}{l}\text { Based on IEA } 6^{\circ} \text { warming sce- } \\
\text { nario and current legislation }\end{array}$ \\
\hline \multicolumn{3}{|l|}{ Control scenarios } \\
\hline No further controls ${ }^{\mathrm{a}}$ & NFC & $\begin{array}{l}\text { Freeze current control levels } \\
\text { after } 2015\end{array}$ \\
\hline Maximum feasible controls ${ }^{a}$ & MFC & $\begin{array}{l}\text { Invest in best available tech- } \\
\text { nologies on all sources by } 2030\end{array}$ \\
\hline \multicolumn{3}{|l|}{ Activity scenarios } \\
\hline Clean fuels in DOMestic sector ${ }^{a}$ & DOM & Replace solid fuels with LPG \\
\hline Clean coal technologies ${ }^{\mathrm{a}}$ & CCT & Construct IGCC power plants \\
\hline $\begin{array}{l}\text { Coordinated global mitigation } \\
\text { strategy }\left(2^{\circ} \mathrm{C}\right)^{\mathrm{b}}\end{array}$ & 2DS & $\begin{array}{l}\text { Based on IEA } 2^{\circ} \text { warming sce- } \\
\text { nario(IEA , 2012) }\end{array}$ \\
\hline $\begin{array}{l}\text { RENewables only in electricity } \\
\text { generation }^{\text {b }}\end{array}$ & REN & $\begin{array}{l}\text { No coal in electricity generation } \\
\text { by } 2050\end{array}$ \\
\hline RENewables tradeoff $^{\mathrm{b}}$ & RENT & $\begin{array}{l}\text { Increasing domestic solid fuels } \\
\text { with higher electricity prices }\end{array}$ \\
\hline
\end{tabular}

${ }^{\text {a }}$ Air pollution reduction scenario.

b Climate change mitigation scenario.

\subsection{Baseline scenario}

The Business As Usual (BAU) scenario is based on energy projections developed by the International Energy Agency (IEA, 2012). In their 2012 report, the International Energy Agency defines this scenario as the $6^{\circ}$-warming scenario. The BAU scenario represents the current policy environment in South Africa in terms of emissions standards, and the energy activity mix is grounded in the projected GDP and population growth presented in Fig. 2a. The energy consumption mix is presented in Fig. 2b, and is dominated by coal. Current air pollution control levels, adapted from Cofala et al. (2012) and Klimont et al. (In preparation), imply that future control requirements will be at least as stringent as current standards (Supplemental, S1). The inputs assume that there will be compliance of existing regulations, except for a few instances for which there have been submissions requesting a delay of enforcement of the regulations. Two instances in which the delayed implementation are taken into account are the mobile sector implementing Euro 5 fuel standards beyond the 2017 deadline, and formal submissions for delays in complying with minimum emissions standards for $\mathrm{PM}$ and $\mathrm{SO}_{2}$ from existing power plants.

\subsection{Control scenarios}

Two control strategies are implemented in GAINS (Table 1). The No Further Controls (NFC) strategy assumes that all emitters are controlled at 2015 levels as implemented in the BAU scenario until 2050. This represents the control scenario with the least costs, since no further investments would be needed after 2015 except to maintain controls. The Maximum Feasible Controls (MFC) scenario represents an option in which emitters in all sectors would implement the best available technology to control all pollutants. These technologies include flue gas desulphurization, high efficiency dedusters, and selective catalytic reduction technologies on industrial sources and power plants, improved stoves and burning techniques in the domestic sector, and the most stringent Euro standards and low-sulfur fuels in the transportation sector (Supplemental, S1).

The implementation in GAINS assumes that all MFC controls are installed by 2030 . These two scenarios form the likely space that the actual emission path will take, and serve as comparisons for the BAU and activity scenarios.

\subsection{Activity scenarios}

Five activity scenarios are implemented to demonstrate how altering the suite of energy activities affects emissions and investments in air pollution controls (Table 1). Activity scenarios are designed as strategies to reduce local air pollution, mitigate GHG emissions, increase energy security through diversity, etc.; however, it is often the case that the benefits of one strategy extend beyond the primary goal. It may be that strategies have unwelcome consequences as well, such as the abandonment of electricity use for cooking due to increasing prices. The GAINS framework allows for the analysis of both multiple benefits and unwelcome consequences and the comparison across scenarios.

Two air pollution reduction strategies are implemented: Clean fuels in the DOMestic sector (DOM) and Clean Coal Technologies (CCT) in electricity generation. The first (DOM) is a strategy that would replace solid fuels with clean household fuels (e.g. liquid petroleum gas) in the domestic sector by 2020, with the goal of reducing the most important source of human exposure to PM in South Africa (Scorgie et al., 2004). The second air pollution approach (CCT) is to employ clean coals technologies in the electricity generation sector. This scenario replaces all new electricity generating capacity - as the current capacity is retired in line with its projected lifetime - with high-efficiency integrated coal-gasification combined cycle (IGCC) plants. While IGCC offers the most promising option for the implementation of carbon capture and storage (CCS), and the technology has been mentioned as a potential strategy in multiple policy documents (Energy Research Centre, 2007; S.A. Government, 2011), the technology is not included in the modeling of clean coal options performed here.
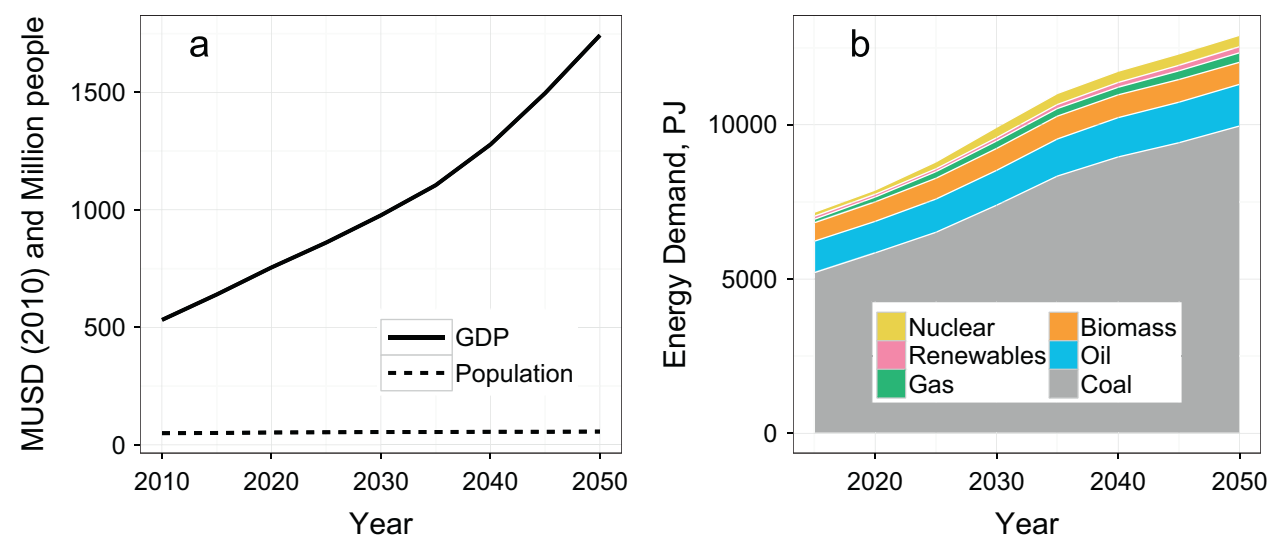

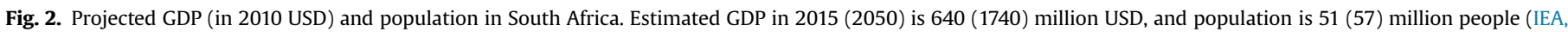

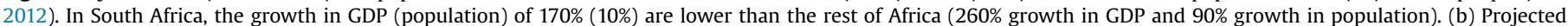
energy consumption by fuel in South Africa the BAU scenario. 
Reported $\mathrm{CO}_{2}$ emissions reductions are driven instead by efficiency increases in the power sector.

Two climate change strategies are implemented. The first (2DS) is an adoption of the coordinated global mitigation strategy aimed at achieving the $2^{\circ}$ warming climate stabilization target as developed by the International Energy Agency (IEA, 2012). The second (REN) is characterized by the replacement of all coal in electricity generation with renewables (e.g. hydro and solar power) and nuclear by 2050. In the 2DS scenario, a majority of the reductions in GHG emissions is gained through switching away from coal use and through the use of CCS in the power generation sector, but changes affect all other sectors as well. Both of these scenarios would require large investments into new energy technologies and infrastructure, including updates to the electricity grid to integrate increased share of renewables. The 2007 LTMS report suggests that these changes are feasible, but would require immediate investment in research and development into the required technologies (Energy Research Centre, 2007).

Both of the climate change mitigation scenarios have a number of air pollution emissions co-benefits. However, past studies in South Africa and elsewhere have provided evidence that increasing electricity prices due to large investments by the electric utility will cause poorer communities to use less electricity for cooking and heating (Madubansi and Shackleton, 2007; OECD, 2012). Instead, these households will turn to cheaper solid fuels (coal, charcoal, and wood), which are the main contributors to particulate exposure. The RENewables Tradeoff (RENT) scenario is modeled using the same replacement of coal with renewables and nuclear as in the renewable scenario, but with a tradeoff of a $10 \%$ reduction in electricity use in the domestic sector and a corresponding increase in domestic solid fuel use. Previous studies have not predicted the extent to which increasing electricity prices will affect electricity use in the domestic sector, so this study provides a stylized example.

Activity inputs for each of the activity scenarios (Supplemental, S2) show the absolute differences in energy consumption by fuels, and how consumption is projected to change over time. The scenarios that involve the adoption of significantly more efficient technologies (notably CCT, 2DS, REN and RENT) require less energy inputs than the others. For example, the CCT scenario, which involves a switch to highly efficient IGCC power plants, requires less coal input to produce the same energy. Activity inputs for the 2DS scenario show the shift from coal toward biomass, renewables, and nuclear.

\section{Results}

\subsection{Business as usual scenario}

Emissions of $\mathrm{NO}_{x}$ and $\mathrm{CO}_{2}$ are projected to grow in 2030 and 2050 under the BAU scenario (Fig. 3). PM $_{2.5}$ emissions will remain relatively constant until 2050, while $\mathrm{SO}_{2}$ emissions will decrease by one third by 2030 and remain relatively stable until 2050 . Projected reductions in $\mathrm{PM}_{2.5}$ and $\mathrm{SO}_{2}$ emissions in the power generation sector are the cause of tightening regulations on emissions, and the realization of these reductions will depend on the ability of the power and industrial sectors to install the controls necessary to meet these standards.

\subsection{Control scenarios}

The two control scenarios show the potential for removing pollutants without changing the activity mixture in the BAU scenario (Fig. 4). For example, $\mathrm{SO}_{2}$ emissions are projected to decrease by over $50 \%$ in the BAU scenario in 2030 compared to 2015 . By not investing in further $\mathrm{SO}_{2}$ controls (the NFC scenario), South Africa would see its $\mathrm{SO}_{2}$ emissions increase due to projected reliance on a fossil fuel driven energy system. Further, an investment in the best available technology to control $\mathrm{SO}_{2}$ (the MFC scenario) would decrease $\mathrm{SO}_{2}$ emissions by another $50 \%$ in 2030 compared to $\mathrm{BAU}$.

Results are considerably different for $\mathrm{PM}_{2.5}$ and $\mathrm{NO}_{x}$. The BAU scenario for these pollutants yields emissions that are much closer to the NFC scenario emissions than the MFC scenario, which would yield a reduction in $\mathrm{PM}_{2.5}$ emissions by $77 \%$ and $\mathrm{NO}_{x}$ emissions by $75 \%$ in 2030 compared to BAU. Therefore, current legislation requires emissions reductions that are much less than potential reductions if investments were made in improved removal technologies. $\mathrm{PM}_{2.5}$ emissions from the electricity generation sector are expected to decrease in the all scenarios largely because of the retirement of older coal plants.

South Africa has a large potential to reduce $\mathrm{NO}_{x}$ emissions in the road transportation sector. Estimated emissions in the BAU case change very little between 2030 and 2050, while implementing maximum controls (which correspond to a shift to EURO 6 engines and fuels) would reduce $\mathrm{NO}_{x}$ emissions by $89 \%$. $\mathrm{PM}_{2.5}$ emissions from road transportation are also projected to decrease in the BAU scenario by 2050 , although controlling emissions to their fullest extent in the MFC scenario would yield emissions that are $32 \%$ of BAU emissions.

\subsection{Policies that affect domestic air pollution emissions}

Domestic activities are projected to contribute the largest share of $\mathrm{PM}_{2.5}$ emissions by 2030 in the BAU scenario (Fig. 4). These emissions are especially important from a public health perspective, as exposure to indoor ambient air pollution is very high for those who cook and heat their homes with solid fuels. The DOM scenario, in which domestic use of solid fuels is replaced with LPG, reduces $\mathrm{PM}_{2.5}$ emissions in this sector by $75 \%$ by 2030 compared to 2015 (Fig. 5), just less than the MFC control scenario. $\mathrm{NO}_{x}$ emissions are reduced by a third in the domestic sector, but this reduction is small in comparison to the total $\mathrm{NO}_{x}$ emissions.
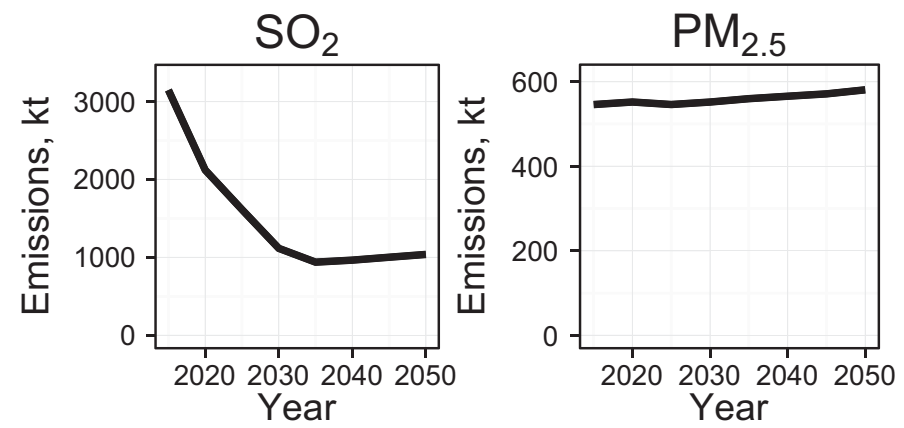
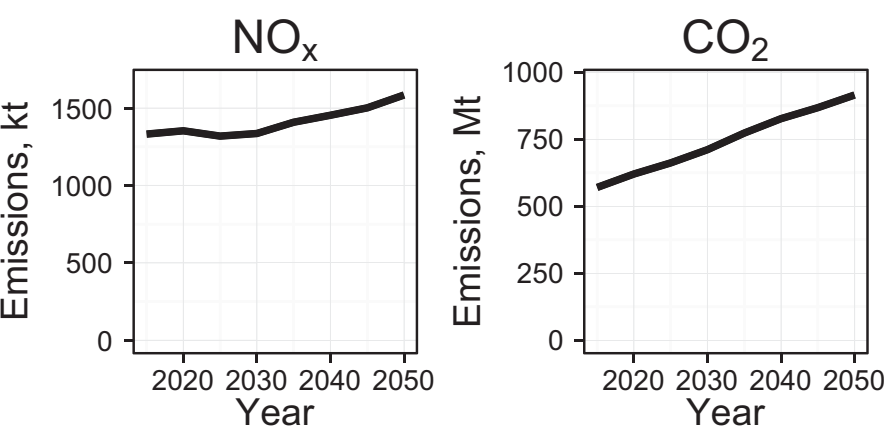

Fig. 3. Estimated emissions under the BAU scenario. 


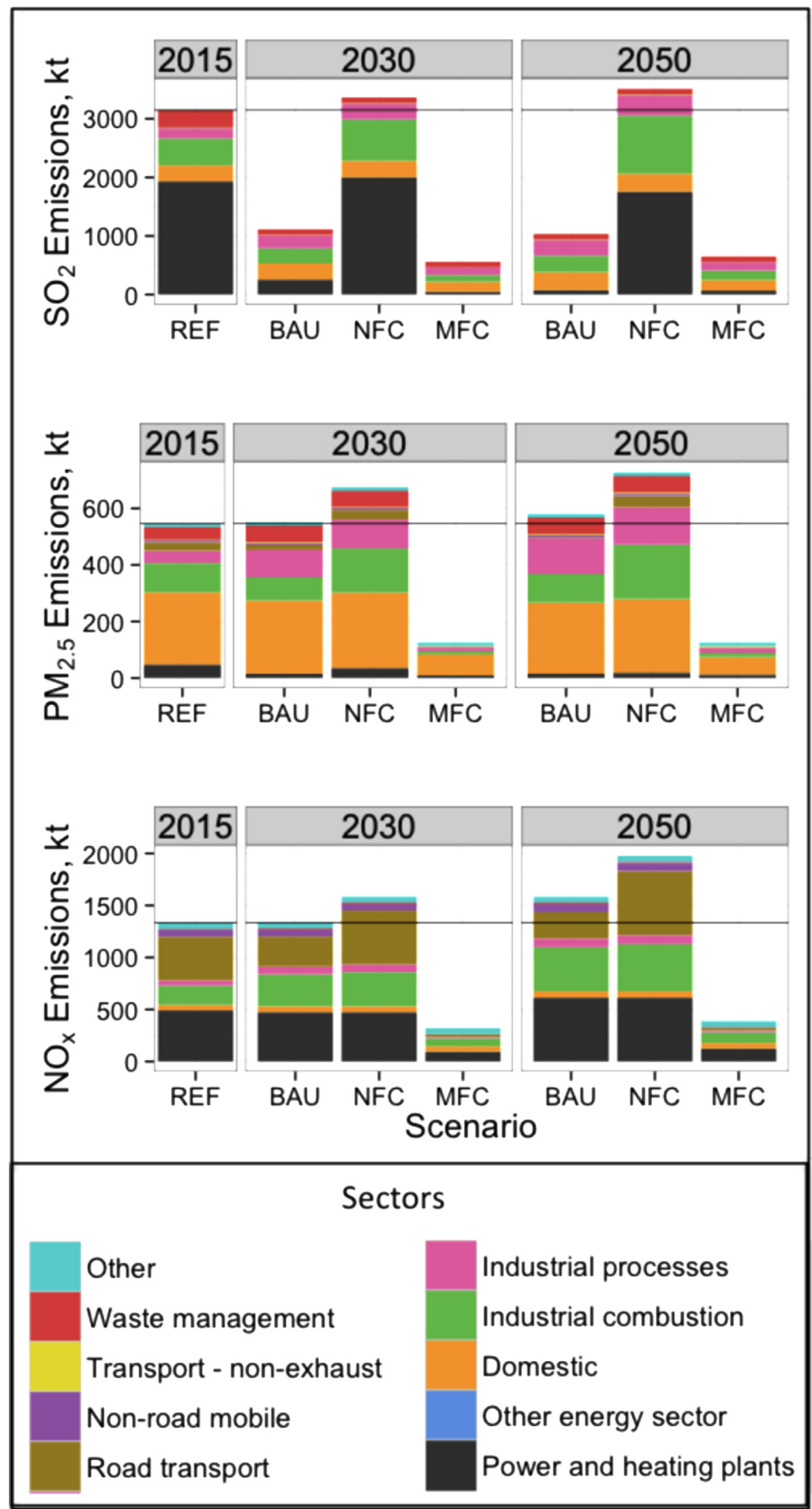

Fig. 4. Emissions in the BAU and control (NFC and MFC) scenarios. REF refers to the estimated emissions for 2015 used as a baseline in all simulations. The horizontal line in each plot corresponds to estimated total 2015 emissions. 

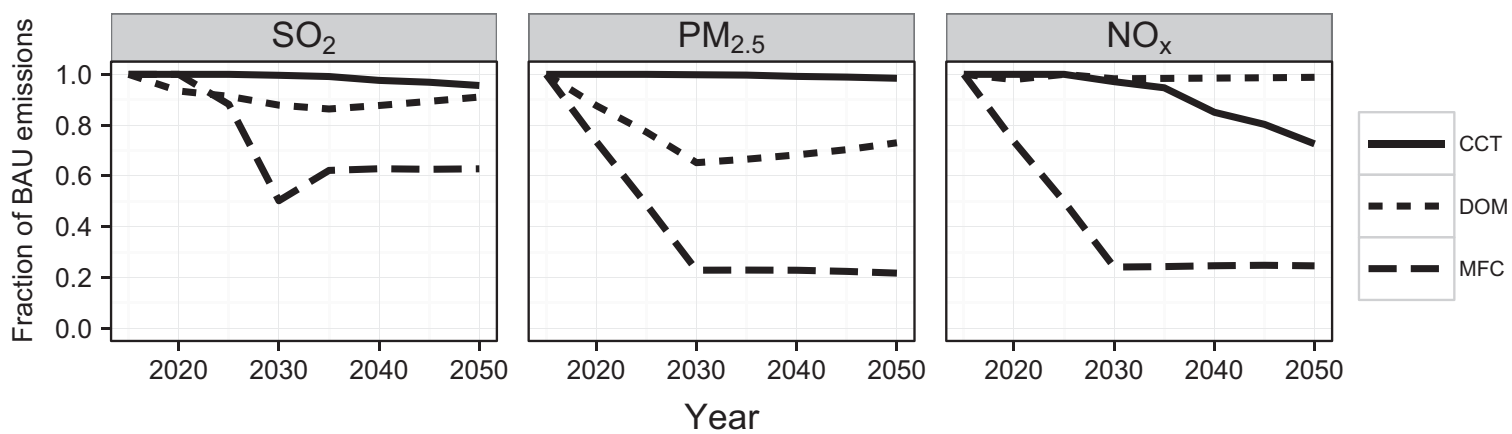

Fig. 5. Emissions in the air pollution reduction scenarios (CCT, DOM, and MFC) scenarios relative to BAU.

Domestic emissions in the REN scenario, which affects emissions only in the power generation sector, do not deviate from the BAU scenario (Fig. 6). If a switch to renewables causes the $10 \%$ decrease in demand for electricity as modeled in the RENT scenario, domestic $\mathrm{PM}_{2.5}$ emissions will increase by $10 \%$ in 2030 and $16 \%$ in 2050.

It is beneficial to compare emissions reductions possible through control scenarios and scenarios that target the dirtiest energy production activities (Fig. 5). When compared to the MFC option, activity options are less effective and slower to implement. For example, controls have the potential to reduce $\mathrm{SO}_{2}$ emissions by nearly $1500 \mathrm{kt}, \mathrm{PM}_{2.5}$ by more than $500 \mathrm{kt}$, and $\mathrm{NO}_{x}$ by more than $1000 \mathrm{kt}$ in 2030 . The two other scenarios aimed at decreasing local air pollutant emissions (CCT and DOM) are not able to remove as much as the MFC scenario, although it is important to note that a combination of these scenarios would produce additive reductions since the two target different activity sectors.

\subsection{Climate change mitigation scenarios}

Three scenarios (CCT, 2DS, and REN) have a substantial effect on both GHGs and air pollution emissions (Fig. 7). Of the three scenarios, the 2DS scenario reduces emissions of all four pollutants most rapidly. The CCT and REN scenarios do not reduce emissions before 2025 because both are designed to allow existing power plants to stay in operation until their projected retirement date. The CCT scenario reduces $\mathrm{NO}_{x}$ and $\mathrm{CO}_{2}$ emissions to a stable level of near $50 \%$ of BAU by 2040 , a value that the REN scenario does not reach until 2050. Further, the 2DS scenario sees the largest benefits for $\mathrm{SO}_{2}$ and $\mathrm{PM}_{2.5}$.

\subsection{Control costs}

GAINS estimates the costs of controls installed for each scenario using a $4 \%$ interest rate (Fig. 8). These costs can be compared to projected GDP to help understand the price in the context of South Africa's total economy (Table 2). As expected, the MFC scenario would require the greatest investments in control technologies, with costs totaling $1.8 \%$ of GDP in 2030 . Costs are avoided in the climate scenarios (2DS and REN) by switching to energy producing activities that do not require air pollution controls (e.g. solar and wind energy).

\section{Discussion}

\subsection{Evaluation of GAINS output compared with previous studies}

A comprehensive bottom-up inventory of South Africa's local air pollution emissions does not exist, although there are plans to develop one (see www.saaqis.org.za/Emissions3.aspx, accessed 11 November, 2015). Four sources provide a point of comparison for the emissions estimated by GAINS (Table 3). The first, the Emission Database for Global Atmospheric Research (EDGAR), is a joint effort under the European Commission to assemble a database of global air pollution and GHG emissions on a grid (EC, 2011). The second is a report compiled for the South African Department of Environmental Affairs (DEA), and presents GHG emissions estimates in South Africa from 2000 to 2010 (Witi et al., 2013). Seymore et al. (2014) compared multiple estimates, and was therefore able to provide an estimate of uncertainty. The earliest year available from this report 2007, is presented alongside the GAINS 2005 value. Van der Hoeven (2011) primarily based the estimates on fuel combustion using the 1996 IPCC guidelines. 2005 is used to compare emissions because this year is available from a majority of the sources.

GAINS estimates $\mathrm{SO}_{2}$ and $\mathrm{NO}_{x}$ emissions to within $30 \%$ and $9 \%$ of the EDGAR values, respectively (Table 3). Major categories, such as electricity production plants, domestic, and transportation emissions match well with the EDGAR estimates. Industrial processes and other sources in GAINS make up the bulk of the difference in $\mathrm{SO}_{2}$ emissions. National estimates of $\mathrm{PM}_{2.5}$ emissions were unavailable to compare to GAINS estimates.

The GAINS estimate of $\mathrm{CO}_{2}$ emissions in 2005 falls squarely in the middle of the four studies used for comparison. A reason for
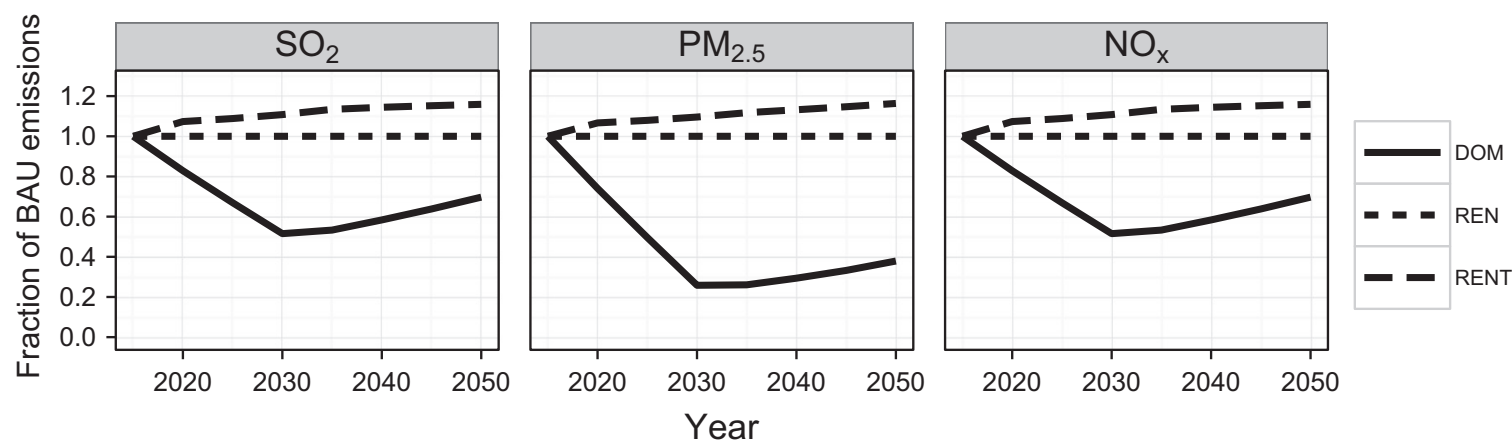

Fig. 6. Domestic emissions relative to BAU for the DOM, REN, and RENT scenarios. 

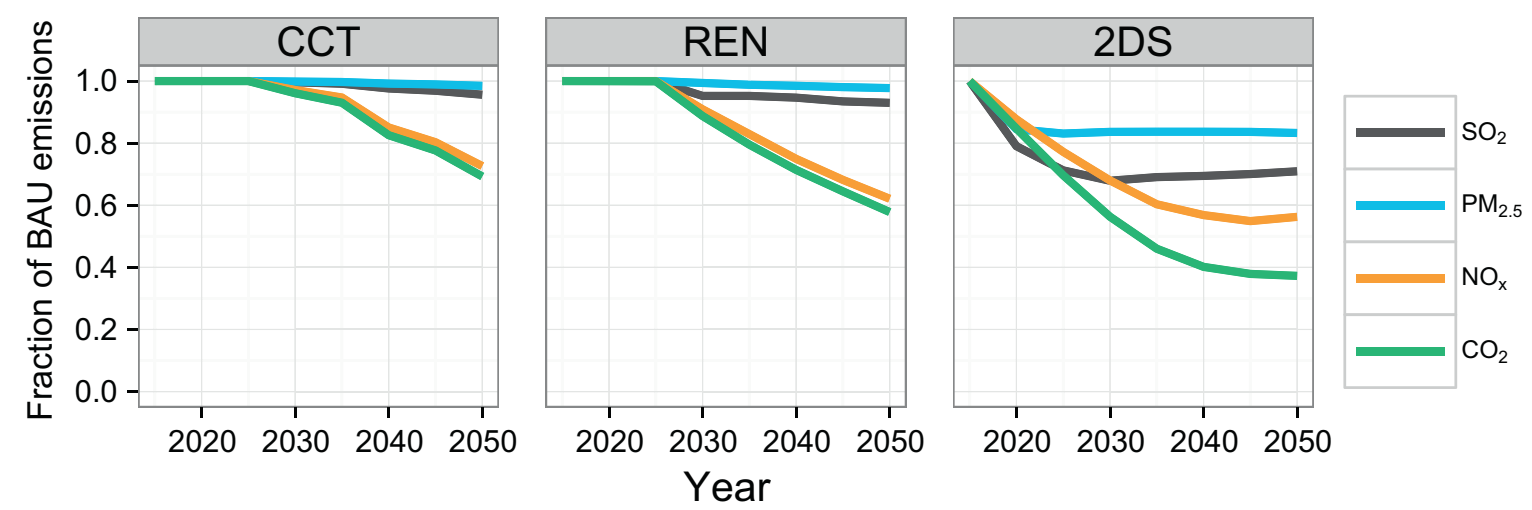

Fig. 7. Total emissions relative to BAU for the CCT, 2DS, and REN scenarios.
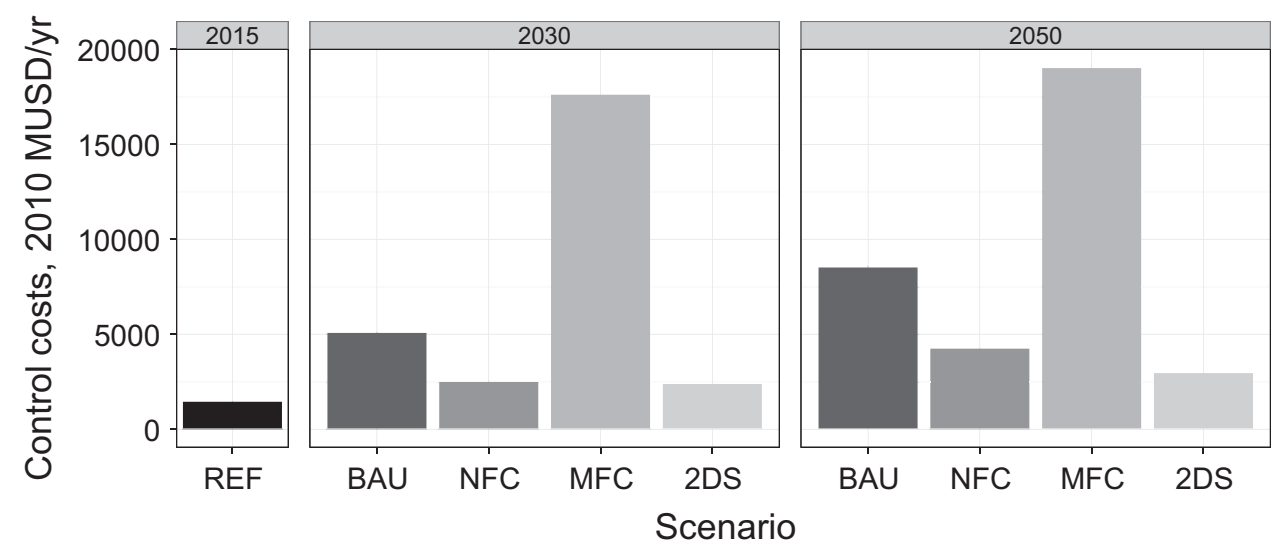

Fig. 8. Costs of emissions controls for selected scenarios in 2010 USD. REF represents the estimated costs for 2015.

Table 2

Control costs for selected scenarios as a percent of GDP.

\begin{tabular}{lll}
\hline Scenario & $\mathbf{2 0 3 0}$ & $\mathbf{2 0 5 0}$ \\
\hline BAU & 0.5 & 0.5 \\
NFC & 0.2 & 0.2 \\
MFC & 1.8 & 1.1 \\
2DS & 0.3 & 0.2 \\
REN & 0.4 & 0.2 \\
\hline
\end{tabular}

Table 3

Comparison of GAINS-estimated emissions to previous estimates in 2005.

\begin{tabular}{llll}
\hline Source & $\mathbf{S O}_{\mathbf{2}}(\mathbf{k t})$ & $\mathbf{N O}_{\boldsymbol{x}}$ (kt) & $\mathbf{C O}_{\mathbf{2}}$ (Mt) \\
\hline GAINS-BAU & 2800 & 1300 & 420 \\
EDGAR (EC, 2011) & 2200 & 1400 & 360 \\
Van der Hoeven (2011) & - & - & 330 \\
GHG-SA (Witi et al., 2013) & - & - & 520 \\
Seymore et al. (2014) & - & - & $465 \pm 38^{\mathrm{a}}$ \\
\hline
\end{tabular}

${ }^{\text {a }}$ Estimate is for 2007.

the higher estimate from the DEA GHG inventory is that the authors estimate nearly $20 \%$ greater emissions for power generation and slightly higher for each of the other sectors in the energy sector (transportation, domestic energy production, etc.). In general, GAINS estimates higher emissions than the methods that rely mostly on fuel consumption data (EDGAR \& Van der Hoeven), and somewhat lower emissions than the other two methods.

\subsection{Air pollution reduction policies}

Both air pollution control scenarios and energy activity scenarios provide pathways for reducing air pollution emissions in South Africa (Figs. 3-6). Results from the MFC scenario show that the country has the potential to reduce emissions of $\mathrm{SO}_{2}, \mathrm{NO}_{x}$, and $\mathrm{PM}_{2.5}$ from all sectors by investing in control options. Controlling emissions from existing sources provides an opportunity for industries to extend the lifetime of current facilities and meet emissions standards. There are costs associated with installing controls, but these costs delay the costs of implementing renewables and other cleaner technologies. However, control options must be considered along with other options (e.g. renewable sources of energy) in the face of limited resources.

Replacing solid fuels with LPG in the domestic sector has as large an effect on $\mathrm{PM}_{2.5}$ emissions reductions as costly controls installed in the industrial and power sectors. Further, emissions reductions in the domestic sector have a large effect on exposure. These policies (i.e. replacing all solid fuel use with clean energy forms) would not come without costs and investments in infrastructure, which are not estimated within the GAINS model.

The CCT scenario option has a number of benefits to South Africa. For instance, emissions of $\mathrm{NO}_{\mathrm{x}}$ from the electricity-generating sector decrease significantly (Fig. 7). Further, $\mathrm{CO}_{2}$ emissions are also reduced compared to the baseline due to gains in conversion efficiency. If carbon capture and storage technologies were developed to a financially viable level, IGCC plants with CCT installed might provide an effective emissions-reduction option for multiple pollutants. Although this technology is costly, such plants may be a necessary option that allows South Africa to encourage economic growth and reduce emissions while continuing to exploit its abundant coal resources. 


\subsection{Climate change mitigation policies}

Climate change policies are developed to contribute to the share of global emissions that must be cut if the world is to remain below a certain level of temperature rise caused by increasing concentrations of GHGs in the atmosphere. Many of the policies, however, also carry the benefits associated with burning less fossil fuel, including reduced local air pollution emissions and associated negative health effects. Costs that are normally associated with implementing technologies (such as emissions controls) to reduce air pollution can instead be invested in renewables or other energy sources with the same result in decreases in emissions.

The 2DS scenario is the most ambitious of the climate scenarios in terms of estimated $\mathrm{CO}_{2}$ emissions. A point of interest is that the scenario does not completely eliminate emissions from coal-fired power plants, instead targeting all sectors. This is in contrast with the REN scenario, which eliminates coal use in electricity production. The 2DS is closest to the scenario presented in the LTMS study, which the authors reported will be difficult to achieve even if South Africa begins to adopt aggressive climate mitigation policies immediately. The REN scenario, therefore, shows an alternative approach that targets only one sector. $\mathrm{CO}_{2}$ emissions are not projected to decrease as much in this scenario (42\%) as the 2DS scenario (54\%) in 2050 compared to BAU, but it provides an option that allows other sectors to function as they would compared to BAU.

\subsection{Policy co-benefits and contradictions}

An advantage of the GAINS modeling platform is that emissions of many air pollutants can be assessed simultaneously for single scenarios. Emissions of GHGs can be estimated for scenarios that are designed to control local air pollutant emissions. The CCT scenario provides one example of this. Even though the scenario is designed to reduce emissions of local air pollutants usually inherent in coal burning (e.g. $\mathrm{SO}_{2}, \mathrm{PM}_{2.5}$, and $\mathrm{NO}_{x}$ ), results show that $\mathrm{CO}_{2}$ emissions are also reduced in this scenario compared to BAU (Fig. 7). In fact, reductions in relative $\mathrm{NO}_{\mathrm{x}}$ and $\mathrm{CO}_{2}$ emissions reductions far exceed reductions in $\mathrm{SO}_{2}$ and $\mathrm{PM}_{2.5}$ emissions for the CCT scenario. Comparative reductions in $\mathrm{SO}_{2}$ and $\mathrm{PM}_{2.5}$ appear lower because current regulations in South Africa require controls in the BAU scenario. Climate change policies (2DS and REN) also yield reductions in local air pollution emissions. The largest reductions for all four pollutants are achieved in the 2DS scenario.

A danger of adopting aggressive climate change policies, however, is the increasing electricity prices that accompany large investments in new technologies (Ürge-Vorsatz and Tirado Herrero, 2012). Newly electrified poorer communities tend to use electricity to supplement their use of solid fuels, usually for lighting and entertainment (e.g. televisions or charging cell phones) (Madubansi and Shackleton, 2006). Deloitte (2011) reported that it is difficult to estimate the effect of electricity pricing on demand, and historically the demand for electricity has been more dependent on income (or GDP) than on price. However, they note that if prices increase beyond a threshold this may change. The RENT scenario attempts to capture this effect by reducing the demand for electricity in the domestic sector by $10 \%$ and increasing the energy input of solid fuels by a corresponding amount. Results from this scenario show that even though reductions in emissions of $\mathrm{PM}_{2.5}$ are realized by adopting the aggressive RENT scenario, emissions from the domestic sector increase by $16 \%$ in 2050 (Fig. 6). Multiple studies have shown that in South Africa, indoor air pollution is the most important contributor to exposure (Scorgie et al., 2003, 2004), meaning this increase would translate into a disproportional increase in negative health outcomes in densely populated poor communities.
Although climate policies have a positive effect on reductions of GHGs in power generation, they must be accompanied with other policies (e.g. subsidies to encourage use of electricity or LPG for cooking) to ensure the strategies do not cause negative effects on emissions from other sectors. These co-benefits and tradeoffs need to be investigated further to ensure the maximum returns are achieved when designing policies to address air pollution and climate change.

A further benefit is the avoidance of costs of controlling air pollutants (Fig. 8). The REN and 2DS scenarios are projected to have lower control costs than the BAU scenario in both 2030 and 2050. In 2050, both scenarios will have total costs of less than the NFC scenario, meaning that changing the activity mix has just as great an effect on control costs as simply maintaining controls at the current levels. These avoided costs serve as a source of savings in otherwise costly climate mitigation scenarios.

\subsection{Policy frameworks for achieving goals in the scenarios}

A companion paper (Klausbruckner et al., In preparation) assesses the current energy and associated environmental policies in South Africa in detail. The authors identify contradictions in the current framework, and discuss opportunities for an exploitation of co-benefits of an integrated approach to managing energy production and use, air pollution, and climate change mitigation policies. They discuss multiple policy tools that could be used to achieve the scenarios detailed above. For example, carbon taxes would encourage a shift towards more of the technologies that are necessary to achieve targets simulated in the CCT, 2DS, or REN scenarios. Such a policy could be further enhanced by offering transfer payments to lower-income households to shield them from price increases that would accompany a large investment into new energy production technologies.

South Africa has enacted regulations to enforce emissions limits from industrial facilities and power plants. To encourage facilities to further reduce emissions through, for example, control retrofits, the country has a number of policy options and examples of their implementation in other regions. For example, $\mathrm{SO}_{2}$ and $\mathrm{NO}_{x}$ cap-and-trade marketplaces have generally been shown to be effective in the United States (Ellerman, 2003; Morgenstern et al. 2012).

In the transportation sector, one limitation to shifting towards advanced control technologies (e.g., the Euro 6 standard) is the continued use of high sulfur fuels, which are incompatible with Euro-6 compliant engines. Further, the persistence of older automobiles limits the penetration of new technologies.

Klausbruckner et al. conclude that the most efficient approach to developing policy must include an integrated assessment of its effects on multiple sectors of the economy (as a whole and on historically disadvantaged communities), public health, and air pollution and GHG emissions. The current work applies GAINS in such an integrated assessment, though the results of the preliminary model are limited in scope and leave room for a more detailed assessment of each scenario.

\section{Conclusion and policy implications}

South Africa's energy intensive economy emits large amounts of air pollution that contributes both to negative health and environmental effects locally and climate change on a global level The GAINS model has been used to assess the impacts of a number of policy options that could be pursued by the country to both reduce air pollution and mitigate GHGs.

Scenarios that target GHG emissions also reduce $\mathrm{SO}_{2}, \mathrm{PM}_{2.5}$, and $\mathrm{NO}_{x}$ emissions by switching away from an economy based on 
fossil fuels, which would translate into lower incidences of negative health impacts caused by air pollution. Further, costs are saved on controlling emissions from conventional technologies (e.g. coal combustion) used to produce electricity.

Care must be taken when implementing policies to encourage controls and changes in activities, since rising prices may encourage poorer communities to switch away from electricity use in their households to more polluting solid fuels. More work is necessary to study how this tradeoff will change with increasing prices and changing income levels. Further development of the GAINS integrated modeling framework will require implementation of parallel dispersion modeling, exposure, and health effects models, and valuation of the public health influences of various scenarios. These adjunct models will increase the value of this type of integrated systems analysis approach as an evidence-based policy support mechanism in reaching decisions in increasingly complex systems of energy, economics, environmental and public health.

\section{Acknowledgments}

This work has been completed as part of the International Institute for Applied Systems Analysis (IIAASA)'s 2014-15 Southern African Young Scientists Summer Program organized by South Africa's National Research Fund and Department of Science and Technology and the University of the Free State, Bloemfontein, South Africa.

\section{Appendix A. Supplementary material}

Supplementary data associated with this article can be found in the online version at http://dx.doi.org/10.1016/j.enpol.2015.11.026.

\section{References}

Amann, M., Bertok, I., Borken-Kleefeld, J., Cofala, J., Heyes, C., Höglund-Isaksson, L., Klimont, Z., Nguyen, B., Posch, M., Rafaj, P., Sandler, R., Schöpp, W., Wagner, F., Winiwarter, W., 2011. Cost-effective control of air quality and greenhouse gases in Europe: modeling and policy applications. Environ. Model. Softw. 26, 1489-1501. http://dx.doi.org/10.1016/j.envsoft.2011.07.012.

Amann, M., Kejun, J., Jiming, H., Wang, S., Wei, W., Jia, X., Chuying, Z., Bertok, I. Borken, J., Cofala, J., Heyes, C., Hoglund, L., Klimont, Z., Purohit, P., Rafaj, P., Schöpp, W., Toth, G., Wagner, F., Winiwarter, W., 2008. Scenarios for cost-effective control of air pollution and greenhouse gases in China. IIASA, Laxenburg, Austria, p. 52.

Cofala J., Bertok I., Borken-Kleefeld J., Heyes C., Klimont Z., Rafaj P., Sander R. Schoepp W., Amann M., 2012. Emissions of air pollutants for the World Energy Outlook 2012 energy scenarios. Final Report to Sponsor: International Energy Agency, Paris, France (June 2012). IIASA Contract no. 12-129. Available from 〈http://www.worldenergyoutlook.org/media/weowebsite/energymodel/doc umentation/IIASA_WEO2012_air_pollution.pdf).

Department of Local Government and Housing (DLGH), 2010. Gauteng Integrated Energy Strategy. Marshalltown, Gauteng, South Africa.

Deloitte, 2011. The economic impact of electricity price increases on various sectors of the South African economy. Report to Eskom, p. 107. Available from 〈http:/ www.eskom.co.za/CustomerCare/MYPD3/Documents/Economic_Impact_of Electrcity_Price_Increases_Document1.pdf $\rangle$.

DOE, 2013. Integrated Resource Plan for Electricity 2010-2030. Department of Energy, Pretoria, p. 73.

Edkins, M.A.X., Marquard, A., Winkler, H., 2010. South Africa's renewable energy policy roadmaps Final Report - June 2010 - for the United Nations Environment Programme Research Project "Enhancing information for renewable energy technology deployment in Brazil, China and South Africa". Cape Town: Energy Research Centre, University of Cape Town, p.41.

EC, 2011. Emission database for global atmospheric research [www document]. Brussels: European Commission. 10.2904/EDGARv4.2 (accessed January 2015).

Ellerman, A.D. 2003. Ex Post Evaluation of Tradeable Permits: MIT-CEEPR (Series); 03-003WP. 〈http://hdl.handle.net/1721.1/44996).

Energy Research Centre, 2007. Long Term Mitigation Scenarios: Technical Summary, Pretoria: Department of Environment Affairs and Tourism, p. 18. Avaliable from 〈http://www.erc.uct.ac.za/Research/publications/07ERC-LTMSTechnical_
Summary.pdf)

IIASA, 2012. GAINS Global. 〈http://gains.iiasa.ac.at/models/index.html〉.

IEA, 2012. Energy Technology Perspectives 2012. International Energy Agency, Paris.

IPCC, 2001. Climate change 2001: synthesis report. In: Watson, R.T., Core Writing Team (Eds.), A Contribution of Working Groups I, II, and III to the Third Assessment Report of the Intergovernmental Panel on Climate Change. Cambridge University Press, Cambridge, UK, p. 398.

Kiratu, S., 2010. South Africa's Energy Security in the Context of Climate Change Mitigation. International Institute for Sustainable Development, Winnipeg, Canada, p. 17 https://www.iisd.org/tkn/research/pub.aspx?id=1331.

Klausbruckner, C., Annegarn, H., Henneman, L.R.F., Rafaj, P., 2015. A policy review of synergies and trade-offs in South African climate change mitigation and air pollution control strategies. Environ. Sci. Policy, In preparation.

Klimont, Z., Höglund-Isaksson, L., Heyes, Ch., Rafaj, P., Schöpp, W., Cofala, J., BorkenKleefeld, J., Purohit, P., Kupiainen, K., Winiwarter, W., Amann, M., Zhao, B. Wang, S.X., Bertok, I., Sander, R., 2015. Global Scenarios of Air Pollutants and Methane: 1990-2050 (In preparation). 〈http://eclipse.nilu.no〉.

Lim, S.S., Vos, T., Flaxman, A.D., Danaei, G., et al., 2013. A comparative risk assessment of burden of disease and injury attributable to 67 risk factors and risk factor clusters in 21 regions, 1990-2010: a systematic analysis for the Global Burden of Disease Study 2010. Lancet 380, 2224-2260. http://dx.doi.org/ 10.1016/S0140-6736(12)61766-8.

Madubansi, M., Shackleton, C.M., 2006. Changing energy profiles and consumption patterns following electrification in five rural villages, South Africa. Energy Policy 34, 4081-4092. http://dx.doi.org/10.1016/j.enpol.2005.10.011.

Madubansi, M., Shackleton, C.M., 2007. Changes in fuelwood use and selection following electrification in the Bushbuckridge Lowveld, South Africa. J. Environ. Manag. 83, 416-426. http://dx.doi.org/10.1016/j.jenvman.2006.03.014.

Merven, B., Moyo, A., Stone, A. Dane, A., Winkler, H., 2014. The Socio-economic Implications of Mitigation in the Power Sector Including Carbon Taxes in South Africa. Working Paper for CDKN project on Linking Sectoral and Economy-wide Models. Energy Research Centre, University of Cape Town, Cape Town.

Morgenstern, R.D., Harrington, W., Shih, J., Bell, M.L., 2012. Accountability Anal. Title IV Phase 21990 Clean Air Act Amendments (168).

Myllyvirta, L., 2014. Health impacts and social costs of Eskom's proposed noncompliance with South Africa's air emission standards. Greenpeace International, Exeter, UK, p. 18 http://www.greenpeace.org/africa/Global/africa/pub lications/Health\%20impacts\%20of\%20Eskom\%20applications\%202014\%20_final. pdf.

OECD, 2012. OECD Environmental Outlook to 2050. OECD Publishing, Available from.

Pauw, C.J., Friedl, A., Holm, D., John, J., Kornelius, G., Oosthuizen, R., van Njekerk, A. S., 2008. Air Pollution in Dense, Low-Income Settlements in South Africa.

Purohit, P., Munir, T., Rafaj, P., 2013. Scenario analysis of strategies to control air pollution in Pakistan. J. Integr. Environ. Sci. 10, 77-91. http://dx.doi.org/10.1080/ 1943815X.2013.782877.

Rafaj, P., Wolfgang, S., Peter, R., Chris, H., Markus, A., 2013. Co-Benefits of post-2012 global climate mitigation policies. Mitig. Adapt. Strat. Glob. Chang. 18 (6) 801-824. http://dx.doi.org/10.1007/s11027-012-9390-6.

Government, S.A., 2011. National Climate Change Response White Paper. Government of the Republic of South Africa, Pretoria, p. 48 http://www.climater esponse.co.za/resources.

SAPIA, n.d. Future Fuel Specifications. www document. Available from 〈http://www. sapia.co.za/key-issues/environment.html (accessed January 2015).

Scorgie, Y., Annegarn, H., Burger, L., 2004. Study to examine the potential socioeconomic impact of measures to reduce air pollution from combustion, Fund For Research into Industrial Development Growth and Equity (FRIDGE). Trade and Industry Chamber, Johannesburg.

Scorgie, Y., Kneen, M.A., Annegarn, H.J., Burger, L.W., 2003. Air pollution in the Vaal Triangle - quantifying source contributions and identifying cost-effective solutions. Clean Air J. 13, 5-18.

Seymore, R., Inglesi-Lotz, R., Blignaut, J., 2014. A greenhouse gas emissions inventory for South Africa: a comparative analysis. Renew. Sustain. Energy Rev. 34, 371-379, http://dx.doi.org/10.1016/j.rser.2014.03.028.

Tait, L., Winkler, H., 2012. Estimating greenhouse gas emissions associated with achieving universal access to electricity in South Africa. J. Energy S. Afr. 23, 8-17 2012.

U.S. EIA, 2013. South Africa: Country Analysis Brief. www document. Available from $\langle$ http://www.eia.gov/countries/country-data.cfm?fips =SF\#cde〉 (accessed December 2014)

Ürge-Vorsatz, Diana, Tirado Herrero, Sergio, 2012. Building synergies between climate change mitigation and energy poverty alleviation. Energy Policy 49, 83-90. http://dx.doi.org/10.1016/j.enpol.2011.11.093 (October).

Van der Hoeven, M., 2011. $\mathrm{CO}_{2}$ emissions from fuel combustion highlights. Int. Energy Agency, 1-134, OECD Publishung, Paris 〈http://www.oecd-ilibrary.org/ energy/co2-emissions-from-fuel-combustion-2011_co2_fuel-2011-en〉.

Wagner, F., Schöpp, W., Amann, M., 2013. Dealing with fixed emissions ceilings in an uncertain future: Offsetting under environmental integrity. J. Environ. Manag. 129, 25-32. http://dx.doi.org/10.1016/j.jenvman.2013.05.054.

Winiwarter, W., 2005. The GAINS Model for Greenhouse Gases-Version 1.0:- Nitrous Oxide. IIASA Interim Report IR-05-055. IIASA, Laxenburg, Austria.

Winkler, H., 2007. Energy policies for sustainable development in South Africa. Energy Sustain. Dev. 11 (1), 26-34 〈http://www.sciencedirect.com/science/arti cle/pii/S097308260860561X).

Witi, J., Stevens, L., Manzini, L., Musee, N., 2013. GHG Inventory for South Africa. 
Department of Environmental Affairs, Pretoria http://www.saaqis.org.za/. Workshop, 2015. Southern Africa sub-regional low sulphur workshop. Co-organized by the United Nations Environmental Programme and the Air Pollution Information Network for Africa. OR Tambo Conference Centre, Johannesburg,
SA. 〈http://www.unep.org/Transport/new/PCFV/africa/sadc_2015.asp〉. World Nuclear Association, 2014. Nuclear Power in South Africa. www document. Available from 〈http://www.world-nuclear.org/info/country-profiles/countrieso-s/south-africa/> (accessed January 2015). 